\title{
Worker's Competency and Perception toward Safety and Health on Forest Harvesting Operation in Indonesian Long Rotation Plantation Forest ${ }^{*}$
}

\author{
Efi Yuliati Yovi ${ }^{1^{*}}$, Seca Gandaseca ${ }^{2}$, I Nyoman Adiputra ${ }^{3}$ \\ 'Department of Forest Management, Faculty of Forestry, Bogor Agricultural University, \\ Academic Ring Road, Campus IPB Dramaga PO Box 168, Bogor 16680, Indonesia \\ ${ }^{2}$ Faculty of Agriculture and Food Sciences, University Putra Malaysia, Malaysia \\ ${ }^{3}$ Faculty of Medicine, Udayana University, Indonesia
}

Received June 16, 2012/Accepted September 7, 2012

\begin{abstract}
Despite of prevention measures such as government regulations and recommendations through technical and managerial researches, unsafe working practices are still a common practice in Indonesia's forestry work, especially in tree harvesting operation. In order to determine competency level of both field supervisor and workers as a baseline in developing participatory occupational safety and health (OSH) protection program, a previously developed competency assessing instrument has been modified. Further, the redesigned instrument was used to verify competency level of field supervisor and forestry workers (chainsawman, hauling workers, and truck drivers) from 6 different forest sites with similar working method. Results showed that both group of respondents had overestimated their competency level in practical aspect, indicated by the gap existence between OSH selfperception value and the standard-based assessment value. The gap significantly occurred in knowledge, skill, and attitude elements; however working attitudes rest in the worst level. This finding then indicated that improving working attitude should be taken as the goal priority in the OSH protection programs in Indonesia. In short, when the discussion is pointed to practical activities, OSH protection program should adapt such strategies which put serious consideration on control mechanism.
\end{abstract}

Keywords: tree harvesting, workers, safety and health, competency, attitude

*Correspondence author, email:eyyovi@ipb.ac.id,telp.+62-251-8621244,fax:+62-251-8621244

\section{Introduction}

It is undeniable facts that forest harvesting operation is a heavy work. The burden had worsen due to combination of hot and humid air, uneven forest floor, biological threats, large and heavy material, and unpredictable wheater resulted in difficult working environment. This working environment triggers additional load to the worker, such as exceeding workload (Takimoto et al. 2004; Yovi et al. 2005ab; 2006) and heat stress (Kroemer et al. 1994; Cullen \& Nadel 1994). Yovi et al. (2005a) mentioned that clear cutting cost physical load to $49-79 \%$ of $\mathrm{V} d o t O_{2} \max$ beyond the permissible workload standard ( $̊$ strand \& Rodahl 1986).

Most of forest harvesting operation in Indonesia is carried out under manual-semi manual system requiring a large labor force and a relatively small investment in capital goods. Serious consideration should be paid to this work productivity-based payment system operation, as most of the workers involved on a basis of self-employed worker. This combination has put work productivity as the worker's priority, and give less attention to safety and health aspects

*This paper is extended version of a paper presented and published as proceeding in the International Scientific Conference "Technology and Ergonomics in the Service of Modern Forestry", June 26-29, 2011, Krakow, Poland.
(Yovi 2009). The most common forestry machine utilized in the operation is chainsaw. Inappropriate chainsaw operations i.e. bad maintenance and lack of safety equipment might worsen effects of gas emission, noise, and vibration (Toyokawa et al. 1996; Wickens et al. 1997; Yovi et al. 2006). Eventhough tropical climate benefiting the worker in a way of lower hand-arm vibration syndrome risk (Futatsuka et al. 1995), the effects of noise and vibration exposures may be exacerbated (Crutchfield \& Sparks 1991) as the workers tend to be more isolated than workers in other types of industry.

Not only awful health problems, the workers are facing serious safety threat also. Data released by ILO (2002) pointed that timber harvesting accident rate in Indonesia had increased from 3,253 cases in 1995 (resulted in 103 deaths) to 4,534 cases in 1999 (resulted in 129 deaths, equal with $9 \%$ of the national total fatal work accidents). The actual rates could be higher, as quantifying the national cases due to occupational injury and illness is difficult, which indicated the lack of good record and documentation system on work accidents (Yovi 2009).

In fact, since 1978 Indonesian Government has issuing several laws and regulations related to $\mathrm{OSH}$ protection related to forest harvesting operation. Eventhough OSHrelated topic still get low consideration from Indonesian 
researchers, since the last decade safety and health topics in forestry works have been adjusted in the university level curricula. However, situation in the field is immensely complex, practices of improper safety and health protection still a common finding in worksites.

This situation has risen fundamental questions related to $\mathrm{OSH}$, in which level the gap were existed, whether it is a problem with the worker's and supervisor's competency or the regulation that not meet with the actual demand? Therefore, this research was aimed to examine the forestry workers by determining the competency level of both the workers and the supervisor, and to discover their perspectives regarding to the importance of $\mathrm{OSH}$ protection implementation in the worksite level. There are 3 elements of competency, namely skill, knowledge, and attitude. Skill is defined as ability to perform a task without conscious monitoring and with other tasks, and knowledge is factual and positional knowledge, and attitude is about perception about ability to perform, willingness, and motivational disposition (Kraiger et al. 1993). This means that the state or quality of being well qualified to perform a task defined as competency (McLelland 1973) should be a critical point, as balance of the 3 elements is very important in developing a competency.

\section{Methods}

All series of competency assessment were conducted in 2009-2012 on long rotation plantation forests located in Cianjur, Ciamis, and Bogor Forest District (FD); all were located in West Java Province. Total respondents were 218, 180 were respondent for competency evalution which were consisted of field supervisor, chainsawman, hauling worker, and truck driver/assistant, and the rest were field supervisor coordinators (30 respondents) and workers ( 8 respondents) for safety and health perception evaluation. All of the forest district implement motor-manual system, i.e. felling by the use of chainsaw, manual hauling/skidding, and $\log$ transporting by the use of truck.
In term of competency evaluation, there were selfassessment (SA) and standard-based assessment (SBA). The SA was directed to explore subjective perception on the workers regarding to their competency in conducting safe forest harvesting operation. Actual competency was evaluated through SBA. The standard used in the SBA was derived from Safety and Health in Forestry Work (ILO 1998) and Ministry Regulation No. 1/1978 regarding to guideline for safe forestry work. Therefore, each standard used in the assessment was fair and legal. The assessment was consisted of 69 fundamental aspects in tree harvesting operations, e.g. pre harvesting activities (felling directions, safety distance, weather conditions, felling preparation), felling and hauling technique, felling equipments, maintenance, safety devices, and related regulations (Table 1). Further, the results of the self-based and standard-based assessments then were compared by the use of Wilcoxon Test. Due to heterogenity on local culture and working environment which could affect the results (Yovi 2009), data taken from each forest district were analyzed separately. The questionnaire was designed on the Likert Scale basis. In the competency analysis, the range of scale and its qualitative value were divided into 1.0-1.8 (very poor), 1.9-2.6 (poor), 2.7-3.3 (modest), 3.4-4.1 (good), and 4.2-5.0 (very good). The questions used in this research were developed from several preliminary researches. Therefore, the data used were only data from questions that had passed reliability and validity test.

A new conceptual framework in occupational safety and health management system noted that safe place, safe person, and safe systems should be considered as main control strategies (Makin \& Winder 2008). However, the succeed of the 3 controls is depend on willingness of at least government, employee, and employer. In term of green products, Yuhainis (2004) mentioned that willingness to pay the green product was influenced by degree of concern and personality, but not with lifestyle of the stakeholders. Based on this finding, series of focus group discussion (FGD) to

Table 1 List of questions

\begin{tabular}{ll}
\hline $\begin{array}{l}\text { Field supervisor } \\
\text { Acts, rules, codes of practice related to OSH* }\end{array}$ & $\begin{array}{l}\text { Chainsawman } \\
\text { Felling, crosscutting, and debranching } \\
\text { techniques and procedures, and its modifications } \\
\text { Maintenance of motor, chain, and guiding-bar of the } \\
\text { chainsaw* }\end{array}$ \\
$\begin{array}{l}\text { How to plan, organize and carry out works to } \\
\text { minimize accidents and health problems risks of } \\
\text { workers* }\end{array}$ & $\begin{array}{l}\text { Mandatory safety features on chainsaw* } \\
\text { Identification of potential hazards and risk control* }\end{array}$ \\
$\begin{array}{l}\text { Kind of safety devices* } \\
\text { OSH guidance for workers* }\end{array}$ & $\begin{array}{l}\text { Potential hazard identification and risk control* } \\
\text { OSH regulations for workers* }\end{array}$ \\
$\begin{array}{l}\text { OSH responsibilities at workplace } \\
\text { Records of accidents and occupational diseases }\end{array}$ & $\begin{array}{l}\text { Truck driver } \\
\text { Maintenance of vehicles* }\end{array}$ \\
\hline $\begin{array}{l}\text { Skidding techniques according to specific local } \\
\text { conditions* } \\
\text { Mandatory personal protective equipments* }\end{array}$ & $\begin{array}{l}\text { National traffic regulations } \\
\text { Workload* }\end{array}$ \\
$\begin{array}{l}\text { Potential hazard identification and risk control* } \\
\text { Potential hazard identification and risk control* }\end{array}$
\end{tabular}


grab actual concern, personality, and lifestyle of both supervisor and workers were carried out. FGD were carried out to grab level of concern, lifestyle, personality, and willingness to pay for safety and health protection. In the FGD, the respondents were asked to categorize their answer under 1-6 scale (1 represents the consent of the weakest and 6 represents the consent of the strongest to the statements mentioned). Respondents in this stage came from 30 different FD, while the workers were chosen randomly from Madiun FD.

\section{Results and Discussion}

Competency assessment Both groups of respondents is dominated by the respondents with a range between 30-39 years of age (Table 2). However, the characteristics of both groups differ from the aspect of work experience and formal education. Field supervisors tend to have longer work experience (6-15 years), while the other groups tend to be dominated by workers who have work experience of less than 5 years. The supervisors also had higher levels of formal education which is relatively better compared to all workers categories.

A timber harvesting supervisor has a responsibility to ensure that timber harvesting is progressing well according to the procedure and the set target. This means, a field supervisor have to make arrangements on logging operations workers, hauling workers, and transportation workers, as well as make quick decisions on technical problems that may occur from time to time, such as completion of snagging a tree fall down the wrong direction or the arrangement of working time due to weather disruptions.

In the context of Indonesia's Qualifications Framework (Kerangka Kualifikasi Nasional Indonesia, KKNI) referred to Presidential Decree No. 8 Year 2012, a field supervisor is required to have the ability to carry out a series of specific tasks independently (supported by the ability to analyze the information obtained), including a full operational knowledge, so he/she capable of solving various problems that may arise during the process of harvesting carried out, and have the ability to collaborate and communicate with in the scope of work. This ability is comparable to work qualification level 3-4 in KKNI. Therefore, the requirement to occupy a position as a field supervisor is a high school education.

In terms of workers, except the truck driver, formal education levels of workers are not very good. All chainsawman and $90 \%$ of hauling workers only have elementary school certificate. In the KKNI context, these workers are categorized as level 1 (for hauling workers) up to level 2 (for chainsawman and truck drivers). Scope of the duties of a hauling worker is very simple, limited, and routine with the help (in there are) of a very simple tools. Meanwhile, the duty of a chainsawman and truck driver is a little more complicated than the hauling workers. Chainsawman and truck drivers are also required to be able to choose the available solutions to problems that commonly arise as to overcome the problem with the truck machines or a chainsaw, or conducting felling under a certain slope or not symmetrical shape of tree canopy.

Data range of age and work experience (Table 2) indicate that the workers likely to start work at the age of 25-30 years. In the 3 forest districts (FD) where the research were carried out, timber harvesting activities are not performed continuously throughout the year. When there was no logging in the forest, a chainsawman can work as part time chainsawman in the village, others work as a technician on a workshop. A hauling worker can work as a daily laborer when there was no logging in the forest, but a truck driver is usually still works as a truck driver with a different type of load. In contrast to field supervisors, workers are paid based on the volume of wood they produced. Further, this wage system encourages employees to focus only on achieving high labor productivity and at the same time ignoring a very important aspect of the safety and health.

As was mentioned before, in order to avoid effect of local work culture that may influenced results of data analysis, analysis was conducted separatedly to each data taken from different FD. Results of the SBA and SA (Table 3) showed

Table 2 Age, work experience, and formal education of respondents for competency analysis study

\begin{tabular}{|c|c|c|c|c|c|}
\hline & \multirow[t]{2}{*}{ Category } & \multicolumn{4}{|c|}{ Percentage } \\
\hline & & Supervisor & Chainsawman & Hauling worker & Truck driver \\
\hline \multirow[t]{4}{*}{ Age (year) } & $19-29$ & 20 & 21 & 14 & 17 \\
\hline & $30-39$ & 60 & 43 & 51 & 37 \\
\hline & $40-49$ & 20 & 25 & 24 & 26 \\
\hline & $50-65$ & - & 11 & 10 & 20 \\
\hline \multirow{5}{*}{ Work experiences (year) } & $\leq 5$ & - & 64 & 53 & 46 \\
\hline & $6-10$ & 45 & 21 & 24 & 23 \\
\hline & $11-15$ & 40 & 14 & 14 & 9 \\
\hline & $16-20$ & 15 & - & 6 & 20 \\
\hline & $>20$ & - & - & 2 & 3 \\
\hline \multirow[t]{3}{*}{ Formal education } & Elementary & - & 100 & 90 & 49 \\
\hline & Junior high & 15 & - & 8 & 31 \\
\hline & Senior high & 85 & - & 2 & 20 \\
\hline
\end{tabular}


Table 3 Results of competency assessment

\begin{tabular}{|c|c|c|c|c|c|c|}
\hline & \multicolumn{2}{|c|}{ Knowledge } & \multicolumn{2}{|c|}{ Skill } & \multicolumn{2}{|c|}{ Attitude } \\
\hline & ${ }^{* *} \mathrm{SA}$ & ${ }^{* * *}$ SBA & SA & SBA & SA & SBA \\
\hline \multicolumn{7}{|l|}{$\mathrm{FD}^{*} 1$} \\
\hline Supervisor & 3.06 & 2.65 & 3.06 & 2.56 & 2.5 & 2.16 \\
\hline Chainsawman & 3.47 & 3.19 & 3.41 & 3.25 & 3.15 & 2.94 \\
\hline Hauling worker & 3.37 & 3.16 & 3.45 & 3.23 & 3.18 & 2.73 \\
\hline Truck driver & 3.76 & 3.16 & 3.76 & 3.29 & 3.47 & 2.98 \\
\hline Total FD 1 & 3.42 & 3.04 & 3.42 & 3.08 & 3.08 & 2.70 \\
\hline \multicolumn{7}{|l|}{ FD 2} \\
\hline Supervisor & 4.04 & 3.57 & 4.08 & 3.60 & 3.91 & 3.62 \\
\hline Chainsawman & 4.18 & 3.47 & 4.24 & 4.03 & 3.99 & 3.78 \\
\hline Hauling worker & 3.77 & 3.06 & 4.00 & 3.49 & 3.70 & 3.43 \\
\hline Truck driver & 4.08 & 3.65 & 4.09 & 3.67 & 4.23 & 3.74 \\
\hline Total FD 2 & 4.02 & 3.44 & 4.10 & 3.70 & 3.96 & 3.64 \\
\hline \multicolumn{7}{|l|}{ FD 3} \\
\hline Supervisor & 4.11 & 3.86 & 4.21 & 3.55 & 3.98 & 3.21 \\
\hline Chainsawman & 4.29 & 4.09 & 4.11 & 3.59 & 3.68 & 2.70 \\
\hline Hauling worker & 3.81 & 3.29 & 3.47 & 3.28 & 3.03 & 2.80 \\
\hline Truck driver & 4.38 & 3.70 & 4.18 & 3.56 & 4.11 & 3.53 \\
\hline Total FD 3 & 4.15 & 3.74 & 3.99 & 3.50 & 3.70 & 3.06 \\
\hline
\end{tabular}

*FD: forest district; $\mathrm{SA}^{* *}$ : self assessment; ${ }^{* * *} \mathrm{SBA}$ : standard-based assessment

Table 4 Wilcoxon Test results between $\mathrm{SA}^{*}$ and SBA**

\begin{tabular}{clccc}
\hline \multirow{2}{*}{ FD } & & \multicolumn{2}{c}{ Asymp. sig. value (2-tailed) } \\
\cline { 3 - 5 } FD 1 & Supervisor & Knowledge & Skill & Attitude \\
\cline { 3 - 5 } & Chainsawman & 0.042 & 0,043 & 0.043 \\
& Hauling worker & 0.021 & 0.010 & 0.011 \\
& Truck driver & 0.002 & 0.001 & 0.008 \\
\hline \multirow{2}{*}{ FD 2 } & Supervisor & 0.004 & 0.041 & 0.006 \\
& Chainsawman & 0.002 & 0.002 & 0.008 \\
& Hauling worker & 0.000 & 0.000 & 0.001 \\
& Truck driver & 0.000 & 0.000 & 0.000 \\
\hline \multirow{2}{*}{ FD 3 } & Supervisor & 0.000 & 0.000 & 0.005 \\
& Chainsawman & 0.011 & 0.005 & 0.002 \\
& Hauling worker & 0.005 & 0.004 & 0.040 \\
& Truck driver & 0.001 & 0.008 & 0.014 \\
\hline
\end{tabular}

$\mathrm{H}_{0} \quad$ : there is no significant different between SA and SBA

$\mathrm{H}_{1}$ : there is a significant different between SA and SBA; $\alpha=0.05$

*SA : self assessment, ${ }^{*}$ SBA: standard-based assessment 
the existence of a gap on each of competency elements on knowledge, skill, and attitude between worker's perception and the work practice standard. In all evaluation, it is obviously can be seen that score for SA were 0.16-0.98 higher than that for SBA. This indicated that all both supervisor and workers tend to overestimate their knowledge, skill, and attitude level. Wilcoxon test (Table 4) showed that the gaps were significantly different. For example, a respondent considered his knowledge regarding to safety devices was "good", but the SBA showed that his knowledge was "poor".

The Table 3 also shows that lower than 3.4 score (the lowest score for "good" category) of SBA were found in FD1 especially for knowledge (3.04), skill (3.08), and attitute (2.70) and FD3 especially for attitude (3.06). The results then confirmed the previous result findings taken from Konawe people forest and Nganjuk Forest District (Yovi 2009). In the study, eventhough the tree harvesting operation were conducted under the similar manner in the harvesting sites and the workers have similar characteristic, the study showed different results. Attitude were the most problem of both sites, but only in Konawe, lacking in knowledge and skill for chainsawman were significant.

Compared to respondents in FD 1 and FD 3, supervisors and workers in FD 2 relatively have a higher competency level. Hauling work for example, in all of the sites were carried out manually. However, almost no handling tools were used in FD 1 and FD 3. This labor intensive work may cause high frequency of muscle contraction, resulted in high energy demand (Yovi et al. 2005a). This energy demand often exceeds the physical limitation of the workers, which in the long run may cause severe health problem (Takimoto et al. 2004). Therefore, the use of simple sulky, a smart choice regarding to its very low procurement and maintenance cost have increased the SBA for hauling workers in FD 2.

In case of tree felling, most of chainsawman in FD 1 and FD 3 abandoned the use of personal safety devices, such as safety shoes, safety helmet, google, gloves, and especially hearing protection. The SDA results indicated that they understand that such safety equipments required during the activities and know how to wear the safety devices properly. But, they also clearly mentioned that they prefer not to wear the devices as the equipments made them feel uncomfortable potentially placed them in the more dangerous situation. In case of refusing to wear earplug, they mentioned that they could not hear important signs when another chainsawman group is about to make back cut, i.e. they stated wearing safety devices will put their safety in more dangerous situation. This perception also was revealed by Carruth et al. (2007) noted that the reason behind personal safety devices ignorance is that the workers considered the safety equipment just causing a communication handicap in work. The similar result also was mentioned by Yovi and Suryaningsih (2011). The study revealed the fact that regardless the fact that the chainsawman understood that the noise could damage their hearing and they can demonstrate in wearing the safety devises properly, uncomfortable feeling when wearing the devices made them hesitate using the devices. An interview with group of workers also revealed the absolute reason why they avoid wearing safety shoes.
They noted that instead make them safe, the shoes often trigger a near miss as the shoes has thick and unbending sole which make their foot finger difficult to "feel" and "grab" the forest floor thus cause them sliding easily. The same direction of opinion was also emerging on the wearing gloves and goggles. Problem in the devises design has also been founded in other country such as Sweden (Svensson et al. 2004). A deeper research on this topic is unquestionable needed, as the most effective protection devices are those which the worker is most comfortable with.

Other examples were loading and transporting activities. Workers in FD 3 use jeep to replace medium duty truck commonly used for log transporting. Jeep was used due to high agility on steep topography which is dominated the forest site in FD 3; however, jeep has a lower capacity than the truck. In field observation, it was a common practice to load exceeds the allowable loading capacity under what the workers said as "economical" reason, pointed to load more $\log$ in a single trip. Field supervisor in FD 3 who actually has the authority did not take any action to prohibit this unsafe practice. Stop the unsafe working method would decreased accident risk, as most of the accident caused by unsafe working method (Lindroos \& Burström 2010). The risk became higher as most of the jeep were modified such that the $\log$ can also be placed on the front nose of the jeep, and a very poor of safety equipment in the cockpit (Figure 1).

The Table 3 clearly shows that implementation of the FD 1 competency improvement programs is far more important than in FD 3 or FD 2. This is due to the SBA of FD 1 in all competency elements that were recognized as "modest" only. Most of the harvesting activities were carried out by ignoring the health and safety aspect. Not even one respondent in FD 1 could mentioned required safety devices in tree harvesting activities properly. During field observation, hung up tree due to improper technique applaid for making felling cut and back cut also happened eventhough the tree were relatively smaller than tree felled in FD 2 and FD 3. And the most severe was the fact that most of the respondent including supervisor have a very low willingness to follow the safe and health work procedure due to several reasons.

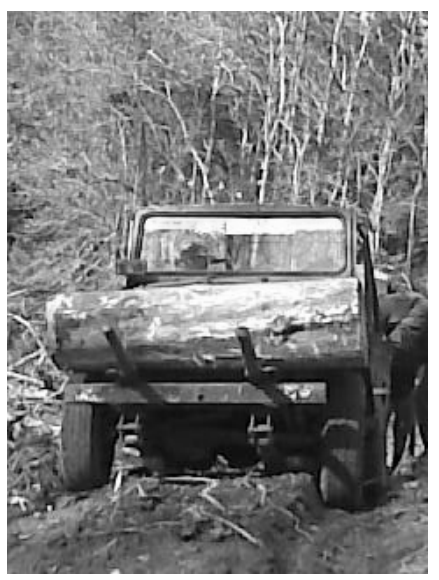

Figure 1 Improper modification. 
Above all of the discussion, the Table 3 indicates that there were serious attitude problems. All respondents categories in FD 1 had been considered as "poor" or "modest" in attitude element. The most surprising fact was that assessment value for attitude of supervisor in FD 1 was 2.16 which is close to the "very poor" category. This condition should be seen as a serious problem (Deming 1986), as management has a very crusial posisiton in assuring the implemention on safety and health protection (Whysall et al.2006). Management should show serious commitment on safety and health protection programs (Alli 2001) as work under safe and health condition is one of human rights as was mentioned in The Universal Declaration on Human Rights 1948 Article 23. The United Nations International Covenant on Economic, Social and Cultural Rights 1976 then reaffirms this right in Article 7. In addition, workers are commercial capital (Brown 2004), and their safety, health and welfare constitute the prerequisite for improving the products/ services quality and productivity (Alli 2001). This means, in the same line with Yovi (2009), attitude improvement programs, started from the management side should get a more serious consideration and be listed as priority.

Perception, lifestyle, and personality regarding to safety and health programs The FGD shows that both supervisors and workers have good concern (level 5 of 1-6 scale) to the importance of safety and health protection. They stated that implementation of safety and health protection program is not merely a fullfilment of legal obligations, but more than that, it should be done as occupational safety and health is a human right. According to their work experiences, human error, and improper management is the dominant cause of incidents while working. Non-compliance with standard operating procedure (SOP), ignorance on personal safety devices, lack of OSH awareness, and incompetent workers were referred as the cause of human error. In the other side, low communication ability, narrow scope of existed SOP, and limited information regarding OSH were referred as the cause of improper management. There are nothing to do with work environment, but a proper working procedure (which were categorized as a part of safe person and safe system) will solve the problems.

This means that both groups have a high preference to preventive action. However, when the discussion pointed to the classical aspect, e.g. cost and limitation on other resources, they firmly mention their objection. For group of workers, this situation can be caused by limitation in economical agility to improve work safety by equiped themselves with the personal safety devices or using a higher safety standard tools, and as for supervisor the reason was mostly because the absence of commitment from top level management.

The FGD also revealed that both of group could be categorized as law-abiding and have good response of responsibility. However, their life-style were very heterogeneous. In some extend, some of respondents in both groups mentioned their strong sense of humanity which is often defeat personal desire. However, it became very interesting when they also mentioned that sometimes they were pragmatic, especially when they being unbale to bear any action reflects their ideal value of personality. At the similar way, this finding is confirming Yuhainis (2004).This situation then raised a question on the effectivity of macro level laws and regulations to perform a good manuever in micro level which closely related with local culture and actual need, means rationality.

This finding then is in the same direction with the competency evaluation. No matter how serious their concern, no matter how good their personality, or how ideal their lifestyle is, as long as there is a bad point in attitude area, there will be no proper action and results come up. In a nutshell, it can be said that attitude which is reflected "mental position" as enabling factor to reach a state of readiness in conducting an action should get serious consideration.

Attitude improvement programs In application stage, enhancing attitude could be attained through several techniques i.e. improving safety equipments design, exposure effect, reinforcement, and changing view point. Re-designing of the safety devices should be done by accommodating the workers opinion. Exposure effect technique requires simple experiences to start the attitude formation by exposing the workers to a concept a number of times. Tools such as video showing safe working method could be useful (Helmkamp et al. 2004). Distribution of pocket book of guidelines for safety in forestry work which explaining proper working technique that could be understood easily and intensive discussion also would be another way in improving their attitude. These techniques, requires strong and consistent commitment of the management board as the attitude changing would take time.

The other technique, reinforcement, implicates a need on incentive-disincentive practices. This technique is based upon the premise that people will repeat a behavior that has desirable results (when the worker shows a good safety and health protection practice during working, then a compliment or grade is given). The last technique, changing the view point requires a comprehensive explanation of direct benefits of OSH protection to the worker. This would be a good practice to change their point of view, as juridical and economical reasons would give a clear impact in the attitude development of the workers. In the end, a participated OSH protection program would be possible if the workers have a proper point of view regarding to the importance of OSH in the working place.

It should be underlined that attitude changing usually would not come in a short time. However, combination of several techniques would give the best results, as Gates and Jones (2007) mentioned the positive impact as a result of combination intervention through noise assessments, educational sessions, mailed reminders with brochures, and placement of hearing protection on the farm. In over all, these efforts therefore would have resulted in greater $\mathrm{OSH}$ protection of the worker, as Burke et al. (2006) mentioned that all methods of training produced meaningful behavioral performance improvements.

\section{Conclusion}

This research showed that insufficient competency level of both supervisor and workers should be considered as one responsible factor for low OSH protection implementation. Therefore, competency improvement on both field 
supervisors and workers should be put in the priority list of forestry programs. The lack was occured in knowledge, skill, or attitude alone or as a certain combination among the three. However, among the 3 elements, attitude, the willingness to conduct an action in a proper way, seemed to be a main issue in this aspect. Further, this research also pointed a new question on the rationality of macro level laws and regulations to perform a good manuever in micro level.

\section{Recommendation}

Combination of improving safety equipments design, exposure effect, reinforcement, and changing view point could be the proper technique to improve the competency level of both supervisor and worker. Strong commitment from all parties also required to create enabling conditions in enhancing the competency level. However, the proper strategies should be determined on the basis of local culture and actual need. Further, how macro level laws and regulations play its important role in the micro and defined level which required special treatments need to be analyzed. This way, OSH protection programs will meet its demand merely stay as a formal and useless programs.

\section{References}

Åstrand PO, Rodahl K. 1986. Textbook of Work Physiology. Physiological Bases of Exercise. New York: McGrawHill New York.

Alli BO. 2001. Fundamental Principles of Occupational Health and Safety. Geneva: ILO.

Brown G. 2004. Vulnerable workers in the global economy. Occupational Hazard 66(4):29-30.

Burke MJ et al. 2006. Relative effectiveness of worker safety and health training methods. American Journal of Public Health 96(2):315-324. http://dx.doi.org/ 10.2105/AJPH.2004.059840.

Carruth A, Robert AE, Hurley A, Currie PS. 2007. The impact of hearing impairment, perceptions and attitudes about hearing loss, and noise exposure risk patterns on hearing handicap among farm family members. American Association of Occupational Health Nurse Journal 55(6):227-234.

Crutchfield CD, Sparks ST. 1991 Effects of noise and vibration on farm workers. Occupational Medicine6 (3):355-69.

Cullen MR, Nadel E. 1994. Thermal stressors. In: Cullen MR, Rosenstock L, editors. Textbook of Clinical Occupational Environmental Medicine. Philadelphia: WB Saunders Publisher. pp658-666.

Deming WE. 1986. Common causes and special causes of improvement stable system. In: Out of the Crisis. Massachusetts: Massachusetts Institute of Technology, Centre for Advanced Engineering Study.pp 309-370.
Futatsuka M et al. 1995. Hand-arm vibration in tropical rain forestry workers. Central European Journal of Public Health 3 Supplement: 90-92.

Gates DM, Jones MS. 2007. A pilot study to prevent hearing loss in farmers. Public Health Nursing 24(6):547-53. http://dx.doi.org/10.1111/j.1525-1446.2007.00667.x.

Helmkamp JC, Bell LJ, Lundstrom WJ, Ramprasad J, Haque A. 2004. Assessing safety awareness and knowledge and behavioral change among West Virginia loggers. Injury Prevention 10(4):233-238. http://dx.doi.org/10.1136/ ip.2003.005033.

[ILO] International Labour Organization. 1998. Safety and Health in Forestry Work. Geneva: ILO.

[ILO] International Labour Organization. 2002. Kode Praktis ILO Keselamatan dan Kesehatan Kerja di Kehutanan. Yanri Z, Yusuf M, Ernawati AW, penerjemah; Elias, editor. Geneva: International Labour Office. Translation from: Safety and Health in Forest Work.

Kraiger K, Ford J, Salas E. 1993. Application of cognitive, skill-based, and affective theories of learning outcomes to new methods of training evaluation. Journal of Applied Psychology78(2):311-328. http://dx.doi.org/ $\underline{10.1037 / 0021-9010.78 .2 .311}$

Kroemer KHE, Kroemer HB, Kroemer-Elbert KE. 1994. Ergonomics. How to Design for Ease \& Efficiency. New Jersey:Prentice-Hall Inc.

Lindroos O, Burström L. 2010. Accident rates and types among self-employed private forest owners. Accident Analysis and Prevention42(6):1729-1735. http://dx.doi. org/10.1016/j.aap.2010.04.013.

Makin AM, Winder C. 2008. A new conceptual framework to improve the application of occupational health and safety management system. Safety Science 46:935-948. http://dx.doi.org/10.1016/j.ssci.2007.11.011.

McLelland DC. 1973. Testing for competence rather than for intelligence. American Psychology 28:1-14. http://dx.doi.org/10.1037/h0034092.

Svensson EB, Morata TC, Nylén P, Krieg EF, Johnson AC. 2004. Beliefs and attitudes among Swedish workers regarding the risk of hearing loss. International Journal of Audiology 43(10):585-93.

Takimoto Y, Yovi EY, Matsubara C. 2004. A study of workload and work efficiency in pine resin harvesting process in plantation forest in Java Island: refreshing work. Applied Forest Science 13:55-62.

Toyokawa K, Ichihara K, Sawaguchi I. 1996. The physiological human response in simple calculation 
work under the impact noise. Journal of Japan Forest Engineering Society 11:173-180.

Whysall Z, Haslam C, Haslam R. 2006. Implementing health and safety interventions in the workplace: an exploratory study. International Journal of Industrial Ergonomics 36:809-818. http://dx.doi.org/10.1016 j.ergon.2006.06.007.

Wickens CD, Gordon SE, Liu Y. 1997. An Introduction to Human Factors Engineering. New Jersey: PrenticeHall Inc.

Yovi EY, Suryaningsih. 2011. Noise, worker perception, and worker concentration in timber harvesting activity. Journal of Tropical Forest Management XVII(2):56-62.

Yovi EY, Takimoto Y, Ichihara K, Matsubara C. 2005a. A study of workload and work efficiency in timber harvesting by using chainsaw in pine plantation forest in Java Island: clear cutting operation. Applied Forest
Science 14(1):17-26.

Yovi EY, Takimoto Y, Ichihara K, Matsubara C. 2005b. Factors affecting workload and work efficiency in pine resin harvesting operations in Java's plantation forests Journal of Japan Forest Engineering Society 20(3): $141-150$

Yovi EY, Takimoto Y, Ichihara K, Matsubara C. 2006. A study of workload and work efficiency in timber harvesting by using chainsaw in pine plantation forest in Java Island (2): thinning operation. Applied Forest Science 15(1):23-31.

Yovi EY. 2009. Assessing OSH protection on forestry work through competency approach. The Indonesian Journal of Physiology 8(2):94-100.

Yuhainis. 2004. Attitude and willingness to pay for green products [thesis]. Kuala Lumpur: University Putra Malaysia. 